\title{
Analisis Risiko Usaha Ternak Di Dusun Koloh Brora Dan Pengenalan Upaya Mitigasi Risiko Melalui Diversifikasi Usaha
}

\section{${ }^{1}$ Lalu Unsunnidhal, ${ }^{2}$ Baiq Nurul Suryawati}

STIKES Yarsi Mataram, Jl. Lingkar Selatan, Mataram, Indonesia. 83361

Universitas Mataram, Jalan Pendidikan No. 36 Mataram, Indonesia 83125

Email Korespondensi: unsun.nidhal@gmail.com

\begin{tabular}{|c|c|}
\hline Article Info & bstract \\
\hline $\begin{array}{l}\text { Article History } \\
\text { Received: } 2019-09-22 \\
\text { Revised: } 2020-06-29 \\
\text { Published: } 2020-06-30\end{array}$ & \multirow{2}{*}{$\begin{array}{l}\text { Livestock Business Risk Analysis in Koloh Brora Hamlet and Introduction to } \\
\text { Risk Mitigation Efforts Through Business Diversification. The purpose of this } \\
\text { community service program is to analyze Livestock Business Risks in Koloh } \\
\text { Brora Hamlet and Introduction to Risk Mitigation Efforts through Business } \\
\text { Diversification. This activity was partnered with a group of livestock in the } \\
\text { Koloh Brorah hamlet with the target of a housewife from the livestock group, } \\
\text { this activity involved } 29 \text { people. The method used is the diffusion of science and } \\
\text { technology. With work procedures, namely 1) planning, action, assistance, and } \\
\text { evaluation. The results of this activity are 1) the formation of knowledge and } \\
\text { understanding of agricultural risks and forms of risk mitigation, 1) the } \\
\text { formation of knowledge and understanding of financial mitigation through } \\
\text { business derification, 2) the formation of business and cake making snacks and } \\
\text { derivation skills. 3) arrange skills in good and hygienic packaging, 4) } \\
\text { understand management in the sale of products from activities. The } \\
\text { recommendation given after the program ends is an effort to increase the } \\
\text { commitment of the wives of farmers to facilitate what has been directed by the } \\
\text { facilitator team. }\end{array}$} \\
\hline $\begin{array}{l}\text { Keywords } \\
\text { Livestock business risks } \\
\text { Mitigation } \\
\text { Deversification of business }\end{array}$ & \\
\hline Infor & Abstrak \\
\hline $\begin{array}{l}\text { Direvisi: } 29-06-2020 \\
\text { Dipublikasi: } 30-06-2020\end{array}$ & \multirow{2}{*}{$\begin{array}{l}\text { Tujuan program pengabdian masyarakat ini adalah untuk menganalisis Resiko } \\
\text { Usaha Ternak Di Dusun Koloh Brora dan Pengenalan Upaya Mitigasi Resiko } \\
\text { Melalui Diversifikasi Usaha. Kegiata ini bermitra dengan kelompok ternak } \\
\text { yang ada di dusun Koloh Brorah dengan sasaran ibu rumah tangga dari } \\
\text { kelompok ternak, kegiatan ini melibatkan } 29 \text { orang. Metode yang digunakan } \\
\text { adalah difusi ilmu pengetahuan dan teknologi. Dengan prosedur kerja yakni 1) } \\
\text { perencanaan, tindakan, pendampingan, dan evaluasi. Hasil dari kegitan ini } \\
\text { adalah 1) terbentuknya pengetahuan dan pemahaman tentang resiko usah ternak } \\
\text { dan bentuk upaya mitigasi resiko, 1) terbentuknya pengetahuan dan } \\
\text { pemahaman tentang mitigasi resiko melalui derifikasi usaha, 2) terbentuknya } \\
\text { keterampilan derifikasi usaha pembuatan kue dan jajanan, 3) terbentuknya } \\
\text { keterampilan dalam pengemasan yang baik dan higienis, dan 4) memahami } \\
\text { menejemen dalam penjualan produk hasil kegiatan. Rekomendasi yang } \\
\text { diberikan setelah program ini berakhir adalah upaya peningkatan komitmen } \\
\text { para istri peternak tersebut agar dapat konsisten menjalankan apa yang sudah } \\
\text { diarahkan oleh tim fasilitator. }\end{array}$} \\
\hline $\begin{array}{l}\text { Resiko usaha ternak } \\
\text { Mitigasi } \\
\text { Deversifikasi usaha }\end{array}$ & \\
\hline
\end{tabular}

Sitasi: Unsunnidhal L. \& Suryawati N.B., (2020) Analisis Risiko Usaha Ternak Di Dusun Koloh Brora Dan Pengenalan Upaya Mitigasi Risiko Melalui Diversifikasi Usaha. Sasambo: Jurnal Abdimas (Journal of Community Service). 2(2), 64-69. DOI : 10.36312/sasambo.v2i2.131

\section{PENDAHULUAN}

Dusun Koloh Brora yang terletak di desa Pemenag Barat Kabupaten Lombok Utara, merupakan salah satu dusun yang masuk dalam wilayah Kecamatan Pemenang. desa 
Pemenang barat memiliki luas wilayah $83,69 \mathrm{~km}^{2}$, dengan lahan sawah $220 \mathrm{Ha}$, Lahan kering $410 \mathrm{Ha}$, lahan pekarangan $27 \mathrm{Ha}$, dan lain-lain 183 Ha. Jumlah dusun 10 dengan RT 68. Dengan Jumlah penduduk laki 6870 Jiwa, perempuan 6872 Jiwa toal keseluruhan total 13,742. jiwa. Rata-rata pekerjaan adalah pertanian dan peternak. Dusun Koloh Brora Desa Pemenang Barat (Badan Statistik Pemenag Barat, 2018).

Dusun Koloh Brora, merupakan salah satu daerah yang terkena gempa di tahun 2018, Berdasarkan data yang disajikan CNN Indonesia yang bersumber dari data Sekretariat Nasional Pendidikan Aman Bencana (SPAB) per 13 Agustus 2018, Khusus di Lombok Utara, 471 orang meninggal, ribuan orang luka luka, 23.098 rumah hancur, 169 satuan pendidikan rusak, 112 masjid roboh, sebanyak 1.117 ruang kelas dan 407 ruangan pendukung, Sedangkan 215 ruangkelas mengalami kerusakan kategori sedang dan ringan. 90 persen sekolah di Lombok Utara rusak. Sejumlah 23.822 siswa SD dan 7.304 siswa SMP berada di pengungsian dan tidak biasa mengikuti proses belajar mengajar normal dalam waktu yang cukup lama. Selain berdampak pada pendidikan gempa juga berdampak pada sektor pertanian, ekonomi, dan sosial (Masjudi, dkk. 2019)(Mashami, dkk. 2019).

Masyarakat di dusun Koloh Brorah berupaya bangkit dari keterpurukan, saat ini mereka pokus dalam memperbaiki tempat tinggal, dan bangkit dengan melakukan aktifitas usaha seadanya, hal yang tidak kalah penting adalah mendorong semangat wirausaha mereka melalui kegiatan-kegiatan sosial, pelatihan, pemberdayaan. Namun dengan kondisi .... tentunya mebutuhkan waktu yang cukup lama dan strategi yang tepat. Peran serta masyarakat sangat dibutuhkan dalam hal ini FKH- UNTB dan FEB-UNRAM sebagai perguruan tinggi di NTB melakukan kegiatan pengabdian yang dapat memberikan dampak pada bangkitnya semangat masyarakat dalam memulai memulihkan perekonomian melalui kegiatan-kegiatan usaha dengan memanfaatkan sumber daya yang tersedia.

Kegiatan pengabdian bemitra dengan kelompok usaha ternak dusun berorah. Selain itu terlibat beberapa pihak antara lain Tokoh Masyarakat di sekitar dusun Koloh Brora, dalam hal ini Ibu RT (Rukun Tetangga) dan Pimpinan Bale Terampil, yang merupakan penggerak wanita di Dusun Koloh Brora; Pihak otoritas seperti istri Kepala Dusun Koloh Brora; Para istri anggota kelompok peternak di Dusun Koloh Brora yang merupakan bagian dari kelompok usaha peternak.

Kegiatan ini dalam pelaksanaanya secara bersama-sama akan melibatkan para istri dari anggota kelompok peternak yang ada di Dusun Koloh Brora, tokoh masyarakat dan tim pengabdian masyarakat dari FKH-UNTB dan FEB UNRAM. Lebih lanjut, tim pengabdian dari FKH-UNTB dan FEB URAM akan menjadi fasilitator untuk membantu membekali para istri kelompok mitra yang ada di Dusun Koloh Brora dengan berbagai macam keterampilan agar dapat membuka usaha sendiri. Pelatihan masyarakat ini dibentuk berdasarkan mutual relationship dimana diharapkan dengan berbagai keterampilan yang diberikan, para istri kelompok mitra, dapat memitigasi risiko usaha yang mereka hadapi dan meningkatkan pendapatan keluarganya. Pelaksanaan pelatihan para istri anggota kelompok peternak ini dilakukan secara bertahap, dan diharapkan dapat memberi peningkatan pendapatan bagi keseluruhan masyarakat di dusun termaksud.

Beberapa kegitan pegabdian menunjukkan kreativitas masyarakat dalam mengembangkan usaha antara lain Sipahelut dkk, (2019) memberikan pelatihan diversifikasi produk hasil ternak di Desa kuaklao untuk meningkatkan nilai tambah ekonomi keluarga dan meningkatka status gizi keluarga terutama anak-anak usia dini dalam pertumbuhan, sementara kendati program di Dusun Koloh Brora berwujud produk berbeda upaya peningkatan keterampilan para istri kelompok ternak yang di desain untuk dapat memberikan penghasilan tambahan dengan mengoptimasi keterampilan tugas para istri kelompok peternak selain berperan hanya sebagai ibu rumah tangga. Hal ini dilakukan sebagai upaya mitigasi risiko karena sumber penghasilan tidak hanya terpusat pada peternakan saja. 
Program ini dirancang untuk dapat meningkatkan keterampilan istri kelompok mitra agar dapat menambah penghasilan keluarga.Tujuan dari kegiatan ini adalah menganalisis Risiko Usaha Ternak Di Dusun Koloh Brora Dan Pengenalan Upaya Mitigasi Risiko Melalui Diversifikasi Usaha.

\section{METODE PELAKSANAAN}

Metode pelaksanaan program pengabdian tentang analisis risiko usaha ternak di Dusun Koloh Brora dan Pengenalan Upaya Mitigasi Risiko Melalui Diversifikasi Risiko dilaksanakan di Dusun Koloh Brora dengan menggunakan metode difusi ilmu pengetahuan dan teknologi (Hunaepi, dkk, 2019). Kelompok sasaran kegiatan ini adalah ibu rumah tangga dari kelompok ternak yang ada di dusun Kola Berorah. Proses kegiatan dilakukan dengan dua tahapan antara lain:

1. Perencanaan

a. Survei dan analisis lokasi kegiatan;

b. Sosialisasi kegiatan melalui diskusi dengan kelompok mitra

c. Persiapan alat dan bahan; proses penyiapan dibantu oleh mitra

d. Pengadan media atau bahan belajar. Untuk kelancaran dan memudahkan peserta kegitan pengabdian dilengkapi dengan buku resep yang disusun oleh tim.

2. Tindakan

a. Penyuluhan, Penyuluhan dilakukan dengan metode ceramah dan diskusi, peyuluhan ditujuan untuk memberikan pemahaman kepada mitra tentang analisis resiko usaha ternak, pengenalan upaya mitigasi resiko melalui diverifikasi usaha, bentuk-bentuk usaha yang dapat dijalan sekala rumah tangga

b. Praktek dan pendampingan, Kegiatan peraktik dilakukan setelah peserta mitra diberikan pengetahuan melalui penyuluhan, adapun yang dipraktikkan adalah diverifikasi usaha pembuatan kue yang dapat dipasarkan. Selanjunya kegiatan pendampingan bertujuan untuk membimbing mitra agar kegiatan dapat berlanjut, selain itu kegiatan pendampingan ini untuk memastikan bahwa setiap orang di kelompok mitra dapat trampil dalam membuat kue sebagai diverifikasi usaha.

3. Evaluasi

Evaluasi dilakukan untuk mengetahui peningkatan keterampilan mitra dalam diverifikasi. Evaluasi dilaksanakan dengan meminta kepada masing-masing anggota mitra untuk memaparkan hasil (proses pembuatan kue, hasil dagang, dll). Jika terdapat kelemahan-kelemahan tim fasilitator membantu menemukan jalan keluar dengan membangun komitmen antar anggota masyarakat untuk membagi tugas. Beberapa anggota masyarakat sepakat mengadakan kerja saman dengan pihak pondok pesantren untuk mencoba memulai usaha jajanan. Tim pengabdian membekali masyarakat dengan buku resep agar dapat membuat variasi jajanan yang lain.

\section{HASIL DAN PEMBAHASAN}

Program Pengabdian telah dilaksanakan selama 7 bulan mulai dari bulan Maret s/d Oktober 2019. Tujuan kegiata pengabdian ini adalah menganalisis Risiko Usaha Ternak di Dusun Koloh Brora dan Pengenalan Upaya Mitigasi Risiko Melalui Diversifikasi Usaha. Usaha yang diperkenalkan adalah diverifikasi usaha kue atau jajanan rumahan. Adapun hasikegiatan pada setiap tahap sebagai berikut:

1. Perencanaan

Survei dan analisis lokasi kegiatan dilakukan untuk mendapatkan informasi kondisi masyarakat yang akan dijadikan mitra dalam legiatan pengabdian. Lokasi survei adalah Dusun Koloh Brora yang terletak di desa Pemenag Barat Kabupaten Lombok Utara. Kegiatan survei dilakukan oleh tim pengabdian. Dari kegiatan survei didapatkan gambaran umum tentang dusun kokoh brorah yang akan dijadikan sebagai lokasi pengabdian. 
Setelah didaptakan hasil survei dan analisi lokasi kegiatan. Dilanjutkan dengan kegiatan sosialisasi dengan kelompok mitra, dan tokoh masyarakat, kegiatan dilakukan di Bale Terampil dusun Kolo Berorah. Adapun hasil dari kegiatan sosialisasi disepakati bahwa kegiatan pengabdian dapat dilakukan dengan jadwal dan waktu yang disepakati bersama, selain sebagai bentuk apresiasi mitra, mitra ikut serta menyediakan alat dan bahan-bahan yang dibutuhkan dalam kegiatan pengabdian.

Kegiatan pengabdian yang dilakukan disambut baik oleh pemerintah desa dan masyarakat mitra, karena selama ini jarang dilakukan kegiatan-kegiatan yang melibatkan masyarakat dalam mengembangkan keterampilan-keterampilan yang dapat berdampak pada peningkatan ekonomi.

2. Tindakan

Tahapan tindakan ini dimulai dengan kegiatan pembekalan materi tentang 1) Analisis resiko usahan ternak, 2) Upaya mitigasi resiko melalui diversifikasi usaha, 3) Jenis-jenis usaha yang dapat dilakukan dengan memanfatakan sumber daya yang ada, dan 4) teknik pembuatan produk berupa kue dan jajan sebagai bagian dari diversifikasi usaha yang memiliki nilai jual. Tujuan dari penyuluhan ini adalah agar masyarakat mitra memiliki pemahaman dan pesrsepsi yang sama tentang materi tersebut. Selain itu dengan adanya pemahaman yang baik akan memudahkan mitra dalam mempraktikkan dalam membuat produk. Penyampaikan materi dalam penyuluhan menggunakan metode ceramah, tanya jawab dan demostrasi. Kegiatan berlansung di tempat terbuka, seperti yang terlihat pada gambar berikut.

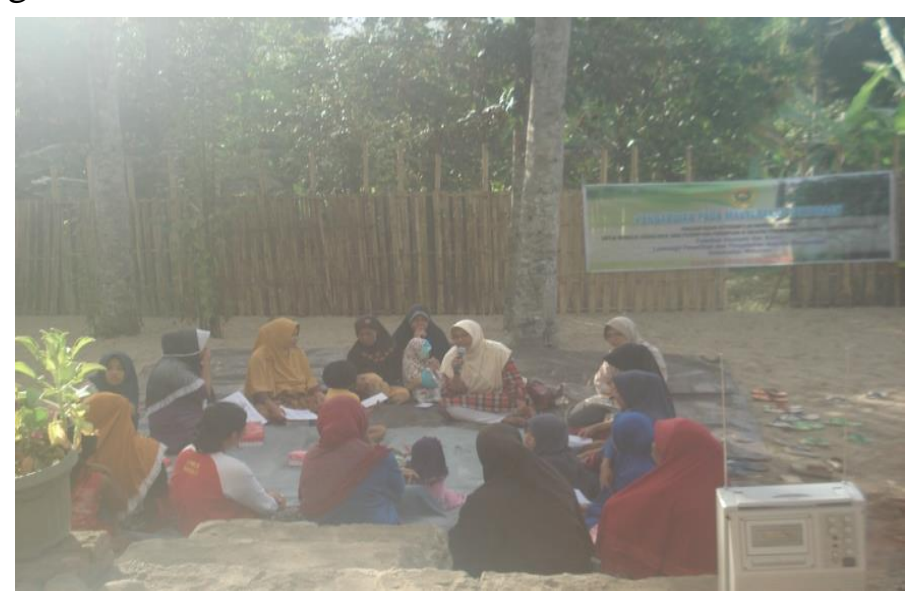

Gambar 1. Kegiatan penyuluhan yang disampaikan oleh tim pengabdian

Proses penyuluhan berlansung dengan baik, ibu-ibu yang terlibat sangat antusias dan semangat, hal ini terlihat dari interaksi tanya jawab pada setiap seasion penyampaian materi, selain itu kehadiran peserta mencapai $95 \%$ hadir pada setiap kegiatan. Untuk mengetahui pemahaman peserta tim pengabdian mengevaluasi dengan melakukan wawancara dan tanya jawab seputar materi yang disampaikan. Hasil dari evaluasi menunjukkan bahwa peserta dapat memahami dengan cukup baik bagian-bagian penting dalam materi yang disampaikan. Materi masih kurang dipahami dijelaskan kembali oleh tim terutama materi yang terkait dengan teknik pembuatan produk berupa jajanan dan kue.

Mitra secara keseluruhan menyataan puas dengan kegiatan penyuluhan dan mereka memiliki pengetahuan dan pemahaman baru tentang materi-materi yang disampaikan dalam kegiatan tersebut.

Setelah dilakukan penyuluhan tim melanjutkan kegiatan dengan pelatihan pembuatan produk berupa jajanan dan kue yang mudah dipasarkan di masyarakat. Kue-kue yang dibuat antara lain roti kukus, pukis, sumping prenggi dan kue putu ayu. Proses pembutan produk berjalan dengan cukup baik karena sebelumnya sudah berikan pemahaman dan resep tentang kue-kue yang dibuat. Adapun proses pembuatan seperti yang terlihat pada gambar berikut. 

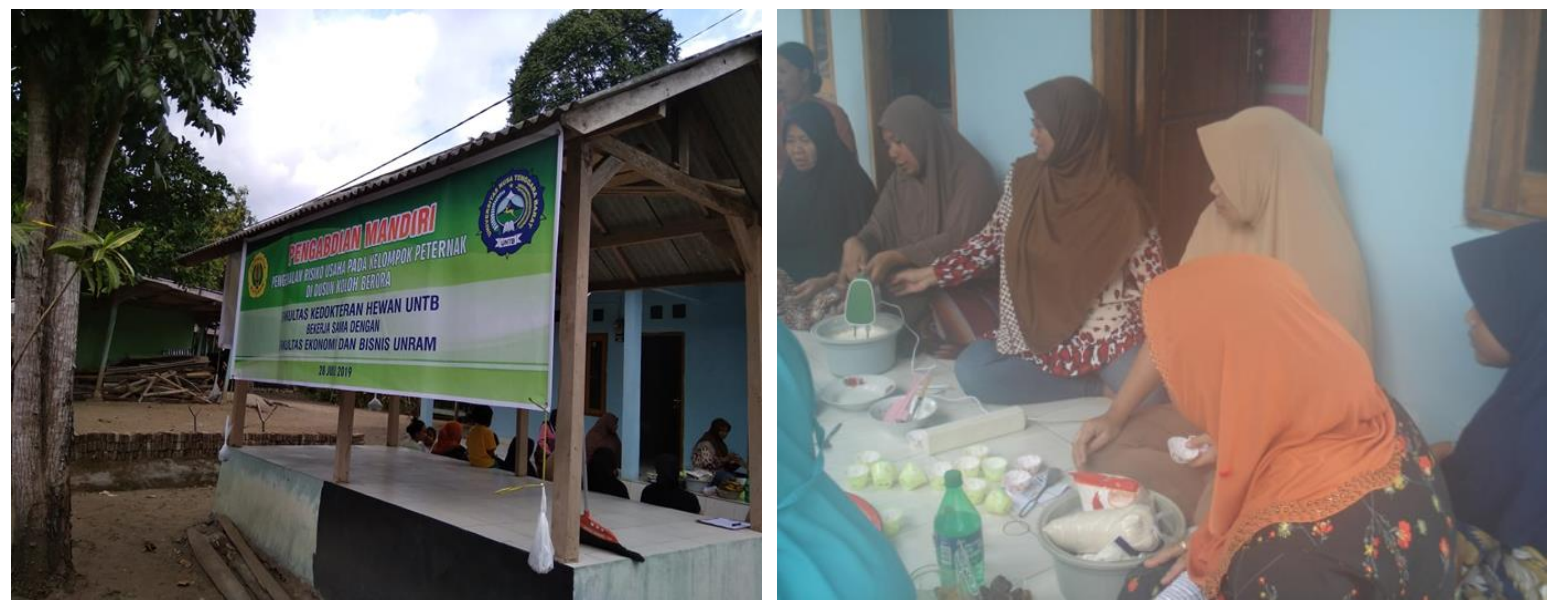

Gambar 2. Proses praktik pembuatan kue dan jajanan

Selama proses pelatihan peserta menunjukkan antusiasme dengan bertanya tentang halhal yang dianggap masih belum dipahami terkait pembuatan adonan, komposisi. Selain itu peserta juga bertanya terkait dengan pengemasan dan pemasaran. Fasilitator mengarahkan para istri anggota kelompok peternak untuk menjalin jejaring usaha dengan bekerja sama dan mencari pangsa pasar secara aktif. Proses tersebut dapat dilakukan dengan sistem jemput bola, antara lain menjalin kerja sama dengan pondok pesantren yang ada di lingkungan Desa Pemenang Barat.

c. Evaluasi

Evaluasi dilakukan untuk mengetahui peningkatan keterampilan mitra dalam diverifikasi. Evaluasi dilaksanakan dengan meminta kepada masing-masing anggota mitra untuk memaparkan hasil (proses pembautan kue, hasil dagang, dll). Jika terdapat kelemahankelemahan tim fasilitator membantu menemukan jalan keluar dengan membangun komitmen antar anggota masyarakat untuk membagi tugas. Beberapa anggota masyarakat sepakat mengadakan kerja saman dengan pihak pondok pesantren untuk mencoba memulai usaha jajanan. Tim pengabdian membekali masyarakat dengan buku resep agar dapat membuat variasi jajanan yang lain.

\section{KESIMPULAN}

1. Program pengabdian dengan memberikan praktek membuat jajanan telah dilakukan untuk membantu para istri peternak melakukan diversifikasi usaha, sebagai upaya meminimisasi risiko usaha ternak sebagai akibat dari gempa.

2. Program pengabdian ini juga memberikan informasi tentang evaluasi usaha dengan memberikan penjelasan praktis bagaimana usaha dijalankan dan pembentukan kelompok usaha dengan komitmen.

\section{SARAN}

Diperlukan sebuah kerja-sama dengan berbagai instansi dan pihak. Kerja-sama yang dimaksud bertujuan mengakomodir keinginan para istri anggota kelompok peternak memulai usaha dengan adanya bantuan modal dari pihak terkait, seperti Dinas Perdagangan, ataupun Dinas Koperasi dan UMKM. Kesulitan mereka dengan pendapatan terbatas, membuat mereka sulit untuk memulai usaha sehingga para istri anggota kelompok peternak ini tidak dapat memulai usaha mereka. Hal ini membutuhkan komitmen dari dinas terkait untuk dapat membantu para istri anggota kelompok peternak di Dusun Koloh Brora untuk memulai usaha rumahan mereka. 


\section{UCAPAN TERIMA KASIH}

Ucapan terima kasih kami haturkan kepada pimpinan Bale Terampil, yang telah dengan sangat kooperatif membantu terlaksananya program pengabdian mandiri ini.

\section{DAFTAR PUSTAKA}

Badan Statistik Pemenang Barat (2018) Kecamatan Pemenang Dalam Angka 2018 Pemenang District in Figures 2018. Maharani. Lombok Utara

CNN Indonesia. 15 Agustus, 2018. Bangunan Rusak, 31 Ribu Anak di Lombok Utara Tak Bisa Sekolah.

Hidayati, E; Heriyanto A; Nuke D I. (2018). Ipteks Bagi Kewirausahaan (IbK) Di Universitas Muhammadyah Semarang.Jurnal Pengabdian Kesehatan STIKES Cendikia Utama

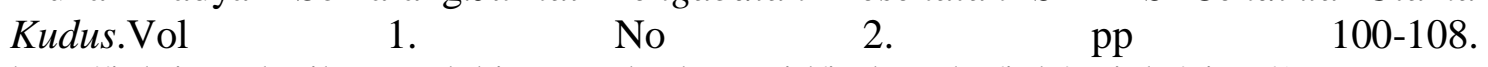
http://jpk.jurnal.stikescendekiautamakudus.ac.id/index.php/jpk/article/view/16

Hunaepi, Asy'ari, M, Samsuri, T., Mirawati, B., Firdaus, L., Fitriani, H., Muhali, Prayogi, S. (2019). Budidaya Jamur Tiram di Pondok Pesantren Hidayaturrahman NW Manggala. Sasambo: Jurnal Abdimas (Journal of Community Service), 1(1), 45-52. doi: $\underline{10.36312 / \text { sasambo.v1i1.119 }}$

Mashami, R., A., Aryani, M., \& Ahmadi (2019) Pemberdayaan Masyarakat Melalui Chemistry

Enterpreneurship di Desa Gondang Kabupaten Lombok Utara. Sasambo: Jurnal Abdimas (Journal of Community Service), 1(1), 15-23. doi: https://doi.org/10.36312/sasambo.v1i1.116

Masjudin., Mujiburrahman., Irawan, D., Zaenudin, M., \& Septiana, W. (2019). KKN KBM Berbasis Masjid Sebagai Model Trauma Healing Berkelanjutan Pasca Gempa di Lombok Utara. Sasambo: Jurnal Abdimas (Journal of Community Service), 1(1), 3644. doi: 10.36312/sasambo.v1i1.122

Rahadi, D. R.; Etty S. (2017). Kreatifitas Kewirausahaan Sosial dan Menggali Ide Usaha Baru Melalui Pengolahan Kripik Tempe Lupin.Jurnal Pengabdian \& Kewirausahaan. Vol. 1 No. 1. pp 17-24. https://journal.ubm.ac.id/index.php/pengabdian-dankewirausahaan/article/view/1002/87

Sipahelut, G M.; Gemini; Malelak, EM;. Dillak, S. Y. F. G; Heri A. (2019). Pengolahan Se'i Babi Pada Kelompok Darma Wanita Di Lingkungan Pemda Sabu Raijua. Jurnal Pengabdian Masyarakat Peternakan. Vol. 4. No. 1. pp 85-92. http://jurnal.politanikoe.ac.id/index.php/jpmp/article/view/259 